\title{
Tourism and Residents' Quality of Life: A Critical Examination
}

\section{https://doi.org/10.33318/jpacs.2019.39(1)-06}

\section{Ilisapeci Matatolu ${ }^{1}$}

\begin{abstract}
This academic paper aims at increasing awareness and understanding of extant knowledge relating to empirical research undertaken on how residents' quality of life (QOL) is impacted by tourism activities. The paper will deliberate related definitions, critically examine selected theoretical frameworks and main themes of extant empirical research in relation to tourism and residents' QOL, with a focus on Pacific context. Strengths and weaknesses of selected theoretical frameworks discussed include social exchange theory, social representations theory and bottom up spillover theory. It also scrutinizes concepts related to how the actions of tourists and the activities of tourism businesses affect indigenous host communities in relation to impacts on residents' QOL. It concludes with an overview of current limitations and future research opportunities encompassing tourism activities and residents' QOL scholarship. Future research opportunities highlighted include an expansion of ontological and epistemological issues in relation to research related to resident atitudes to tourism and quality of life in indigenous communities.
\end{abstract}

Keywords: indigenous communities; quality of life; resident perceptions; tourism; tourism activities

\footnotetext{
${ }^{1}$ Teaching Assistant, School of Tourism and Hospitality Management, The University of the South Pacific, Fiji. email: ilisapeci.matatolu@usp.ac.fj
} 


\section{Introduction}

The global focus of rising overtourism makes it imperative for tourism research to focus on the quality of life of local residents and how it is impacted by tourism activities. Subsequently, an area gaining increased attention in tourism scholarship is the link between tourism activities, and its impacts on the quality of life of residents who live in tourism-active communities (Ouyang, Gursoy, \& Chen, 2019; Gursoy, Ouyang, Nunkoo, \& Wei, 2019; Movono \& Becken, 2018). A tourist destination that delivers a rich QOL for its residents can sustain offering high-quality tourism experiences, while a destination that delivers poor QOL for its residents may offer an inadequate tourism experience (Uysal, Perdue, \& Sirgy, 2012). Tourism academics have explored the contribution that tourism makes to various aspects of QOL of residents of tourism-active communities (Ma \& Kaplanidou, 2017; Moscardo, 2009). The concept of QOL “is concerned with understanding people's perceived satisfaction with the circumstances in which they live" (Moscardo, 2009, p. 162). As a term, it is difficult to define and "is considerably value laden and values differ across individuals and cultures" (Lloyd \& Little, 2005, p. 150). The study of QOL dates back to early twentieth-century research carried out in the United States, which sought to evaluate standards of living. Expanding beyond the social sciences in the 1970s, the study of QOL provides a basis for understanding the ways in which various factors in a person's situation influences that person's sense of wellbeing (Orange, 1995; Suntikul et al., 2016).

QOL research studies ways in which factors in a person's social environment contribute to or detract from the quality of people's lives. QOL measurement refers to a scale that differentiates between "better" and "worse" perceived states. These factors are either subjective - related to one's perceptions and feelings - or objective - related to measureable or tangible aspects of the possibilities and resources a person has access to (Campbell, 1974).

Based on desk research and a systematic literature review, this paper reviews definitions and conceptualizations of tourism and QOL and critically examines selected theoretical frameworks and main themes of extant empirical research, with a focus on Pacific context.

\section{Tourism and Quality of Life}

Tourism activities can affect the QOL of a community that has embraced tourism development by way of social, economic, cultural, and environmental impacts (Moscardo, 2009; Cecil, Fu, Wang, \& Avgoustis, 2010; Khizindar, 2012; Kim, 
Uysal, \& Sirgy, 2013; Nunkoo, Smith, \& Ramkissoon, 2013; Sharpley \& Telfer, 2014). A community embraces tourism based on the premise that an increase in income from tourists will improve the community's QOL (Andereck \& Jurowski, 2006). Kim (2002) undertook one of the first studies that linked tourism impacts and QOL. The result of her study indicated that residents perceived tourism impacts and these in turn influenced their sense of well-being in both subjective and objective terms.

As a multidimensional concept, resident QOL is impacted by tourism activities (Sharpley \& Telfer, 2014). These impacts are both negative and positive and they have significant implications for tourism policy makers and practitioners. More importantly, these impacts come at a cost, in particular on the local people who act as "hosts" to tourists (Wall \& Mathieson, 2006). Positive resident perceptions of tourism is a critical factor in tourist satisfaction and is vital for a successful tourism industry (Andriotis \& Vaughan, 2003).

A "happy host" or the goodwill of local residents is a critical component for a sustainable tourism industry (Jurowski \& Gursoy, 2004). Two key tourism development models, Doxey's Irridex Model and Butler's Tourist Area Lifecycle model outline the extrinsic dimension that closely relate to tourism development and community reactions. Doxey's (1975) Irridex model suggests that resident attitudes towards tourism may pass through a series of stages, from euphoria, through apathy and irritation to antagonism as perceived costs of tourism exceed benefits. These progressive stages and Butler's (1980) tourist area life cycle model are closely linked. There is a close parallel to adverse community reactions to tourism development in line with the growth of mass tourism in destinations. It is therefore imperative that academic research continue to play a pivotal role in improving QOL for residents, tourists, and other major stakeholders in terms of measurement, policy and direction frameworks.

Kim (2002) undertook one of the first studies that tried to link tourism impacts and QOL. She experimented with a model that links community residents' perceptions of tourism impacts (social, cultural economic, environmental) with resident satisfaction with particular life domains (including material, community, emotional, health and safety wellbeing) and life satisfaction. The results from her study indicated that residents perceived tourism impacts and these in turn influenced their sense of well-being in various life domains, which in turn affect overall QOL.

The positive and negative impacts of tourism is an area that has been widely 
researched in tourism studies (Andereck, Valentine, Knopf, \& Vogt, 2005; Pizam, 1978). Wall and Mathieson's (2006) pioneering work on tourism impacts showed that tourism impacts, both positive and negative, can be seen from several different perspectives: economic, social, cultural and environmental. In relation to positive economic impacts, literature shows tourism helps improve standard of living (Belisle \& Hoy, 1980), increases investment (Liu \& Var, 1986), increases business opportunities (Prentice, 1993). Negative economic impacts of tourism, as shown by the literature, include inflated property taxes (Perdue \& Gustke, 1991), inflated prices of goods and services (Weaver \& Lawton, 2001), and land price increases (Lundberg, 1980). Social impacts of tourism can be both positive and negative. Negative social problems cited in extant literature include traffic congestion problems, overcrowding of public spaces, and littering. Social problems also include gambling, prostitution, begging, cultural deterioration, and drug trafficking (Andereck et al., 2005).

Literature also highlights that tourism can have positive and negative influences on culture. Tourism has often been criticized for disrupting or weakening traditional cultural practices, to some extent exploiting culture for commercial purposes (Pearce, Moscardo, \& Ross, 1996). On the positive side, tourism is viewed as a major force for rejuvenating cultural practices (Wall \& Mathieson, 2006). For example, tourism activities have led to transformational change and contributed to the upgrading of public facilities like outdoor recreation facilities, parks, and roads (Liu \& Var, 1986; Perdue \& Gustke, 1991).

Tourism activities can also have positive and negative impacts on the environment. The literature points out that tourism boosts a greater awareness of the need to preserve the physical environment for tourist purposes and increasing investment into the tourism infrastructure of the host country (Var \& Kim, 1989). Often touted by environmentalists as a clean industry, tourism is also seen to reduce pollution and improve the physical appearance of communities (Perdue \& Gustke, 1991). On the other hand, tourism is also seen as a major contributor to environmental problems like pollution, destruction of natural resources, and depletion of wildlife (Var \& Kim, 1989).

\section{Definitions of Quality of Life}

QOL, as a universal concept, appears in academic literature dating back to Plato and Aristotle, and grew out of a concern that economic indicators were not sufficient to adequately measure the QOL of populations (Rapley, 2003). Researchers have articulated different meanings to the term, "quality of life", and also pointed out that 
the term itself was used interchangeably with words like "happiness", "life satisfaction", "well-being", "welfare", which were quite similar in terms of interpreting human values and virtues (Easterlin, 2003; Veenhoven, 2000). Literature shows that there are many existing definitions of QOL, and there is no consensus on an industry standard definition. QOL is also multidimensional in nature (Moscardo, 2009; Schuessler \& Fisher, 1985; Uysal, Sirgy, Woo, \& Kim, 2016). Nobel laureate Amartya Sen (Sen, 1999) argued that the definition of QOL should move beyond economic indicators.

\section{Definitions Used by International Organisations}

We will now briefly look at several definitions that are being used by major international organizations to assist us in this discussion. The World Health Organization (WHO, 2019) defines QOL as:

individual perceptions of their position in life in the context of the culture and value systems in which they live and in relation to their goals, expectations, standards and concerns. It is a broad ranging concept affected in a complex way by the person's physical health, psychological state, level of independence, social relationships, and their relationships to salient features of their environment.

In relation to the above definition, the dominant measuring instrument widely used by the WHO is called the World Health Organization Quality of Life Instrument (WHO-QOL), which references six main broad domains of QOL: physical, psychological, level of independence, social relationships, environment, economic and spiritual domains (Pukeliene \& Starkauskiene, 2011). As the leading global authority on health, the WHO's definition revolves around health-related QOL issues to encompass a multi-dimensional construct that includes physical, mental and social domains. These include measurements in relation to living standards, life expectancy, literary rates, and socio-economic status (Saxena et al.,1997). However, recent research has questioned the efficacy of this definition as lacking the scope to include other elements that are deemed important by communities. For example, McCabe and Johnson (2013) discuss the fact that there is more to life than satisfaction, and suggested the inclusion of personal development into the framework of the existing definition to make it more relevant to today's QOL landscape. It may also be argued that the WHO definition is based on developed countries understanding of QOL, and this may be quite different from how communities in less developed countries perceive QOL (Buzinde, Kalavar, \& Melubo, 2014; Usher \& Kerstetter, 2014). For example, recent research on indigenous communities on tourism and quality of life 
in Tanzania show that these communities place a high priority on land, cattle, and children in terms of QOL measures that may suggest that the values or priorities of these communities are quite different from those of the developed world.

The Organization for the Economic Cooperation and Development defines QOL as "the notion of human welfare (well-being) measured by social indicators rather than by quantitative measures of income and production" (OECD, 2007, p. 6340). When compared to the World Health Organization definition, it is clear that the OECD definition focuses on the values of things over and above income and production. At an individual level, Hagerty et al. (2001) define QOL as a term that implies the quality of a person's whole life, not just a separate component part. Cummins (1997) defines QOL as being both objective and subjective, each axis being the aggregate of seven domains: material wellbeing, health, productivity, intimacy, safety, community, and emotional wellbeing. Objective domains include culturally relevant measures of objective wellbeing, while subjective domains cover domain satisfaction weighted by the importance to the individual.

The United Nations refers to the Human Development Index (HDI) covering three specific dimensions: a long and healthy life, knowledge, and a decent standard of living (Massam, 2002). The HDI was developed in response to the recognition that GDP, as a measure of a country's wealth, was not representative, or a holistic measure of a country's well-being. Other macro-economic measures included by the HDI index include not only economic variables (GDP), but also education (literacy and student enrolment) and health (life expectancy, mortality rates), in order to provide a better understanding of "wellbeing". A study situated in Nicaragua used the HDI index in the context of tourism, and found that tourism development triggered human development (health, education, living standards), which subsequently further develops tourism (Croes, 2012).

At this point, it is appropriate to point out that recent research on QOL has focused on two main measurement methodologies: subjective well-being and objective wellbeing. Subjective wellbeing, focusing on attitudes and feelings, centres on issues like happiness, pleasure and fulfilment (Diener \& Lucas, 1999; Easterlin, 2003). Objective wellbeing focuses on measurable or quantifiable elements of QOL, like food and shelter, and can include indices of economic production, e.g. Gross Domestic Product, literacy rates, and life expectancy (Constanza et al., 2008). The literature also notes that there is a move to integrate or combine objective and subjective approaches, as there is widespread belief that there is an overlap between each domain (Andereck \& Jurowski, 2006). Moscardo (2009) posits that even though 
there is no consensus on a common definition, there is considerable agreement on the key elements of QOL. These include basic physiological needs (food, water, good health, physical protection from harm), security (including a stable place to live and work), belongingness (including links to supportive social networks and opportunities to participate in social, cultural and political activities), and self-esteem (including knowledge and confidence, and the ability and freedom to make choices).

\section{Key Domains}

Academic scholars have highlighted key domains when investigating QOL, including material, health, productivity, intimacy, safety, community, and emotional well-being (Kim et al., 2013). Cummins (1997) also looked at studies that covered 173 descriptors of life satisfaction that covered each of the domains in detail. Kim et al. (2013), in examining the concept of overall QOL, also looked at four key domains: material wellbeing, community wellbeing, emotional wellbeing and health and safety wellbeing. In their study, standard of living, income, and employment were covered under the well-being domain, while leisure activity and spiritual activity were covered under the emotional wellbeing domain.

So, what is QOL, and which domains are more important than others? Angus Campbell, widely considered the father of QOL research, talks about the term as being similar to the word, "ecotourism", in the sense that everyone uses it but no one clearly knows what it means; he refers to it as an ambiguous and ethereal entity (Campbell, 1974). Perhaps this refers to the fact that QOL is inherently abstract concept that has to be made concrete to be clearly understood. This is further complicated by the proliferation of various models, scales, domains and frameworks.

\section{Universal Definition Elusive}

It is clear from the above discussion of definitions of QOL that achieving a common or united platform to define QOL remains elusive, particularly in terms of measurement, definition and policy. As with all academic research, it is critical to have definitions so that the scope and boundaries of debate is clear. Perhaps, given the broad, multidisciplinary and multidimensional nature of the concept, as well as the objective and subjective scopes of meanings, this elusive issue may take time to be addressed by both academics and practitioners alike. Perhaps an integrated approach that uses a multidisciplinary approach that considers the values of the residents, tourism development needs, and sustainable principles could arrive at a new position that caters for all related players and priorities. This paper suggests that within the process of coming to a widely-accepted definition of QOL, care should be 
taken to ensure that each person is treated as an individual and their individual values, perceptions, and priorities in relation to their environment, economy and society.

A very simple diagram (Figure 1) below shows the key elements that represent the main domains of QOL. The diagram illustrates that QOL is divided into four domains: material wellbeing, health and safety wellbeing, community wellbeing, and emotional wellbeing. Income and employment, and costs of living are elements that are included in the material wellbeing domain. The provision of community service and facilities, and resident wellbeing are included under the community wellbeing domain. Emotional wellbeing covers issues that include quality of leisure time and activities, and richness of cultural life. Health and safety wellbeing covers issues like air and water quality, in addition to safety and security considerations (Kim et al., 2013; Sirgy, Widgery, Lee, \& Grace, 2010) .

Figure 1. The Effect of Tourism on Quality of Life

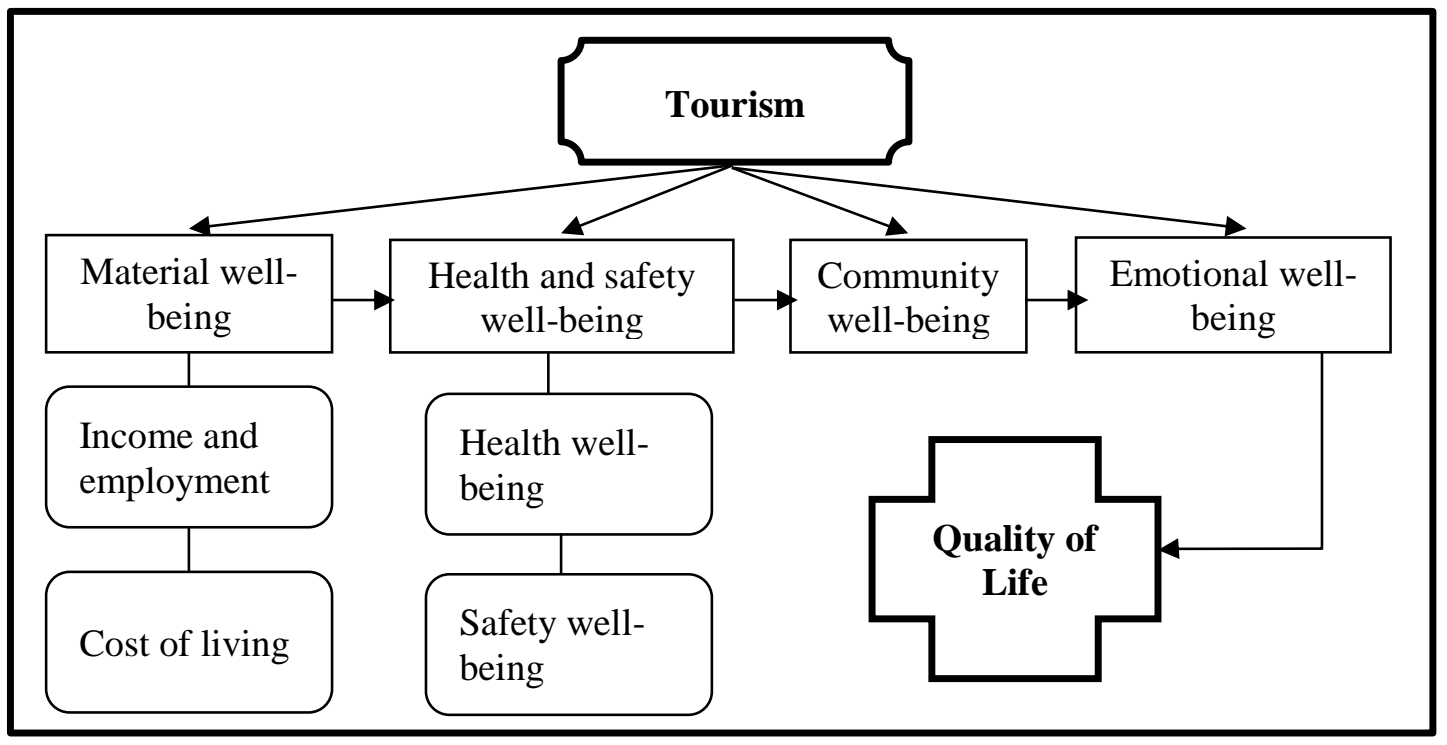

Source: Sirgy, 2011

\section{Examining Selected Theories of QOL}

The literature suggests that several theoretical frameworks dominate the discussions on tourism activities and QOL. For the purpose of our discussions, three major theoretical frameworks are highlighted for dialogue. They include social exchange theory, social representations theory, and Bottom up spillover theory. 


\section{Social Exchange Theory}

Social exchange theory, adapting principles from behavioral psychology theory and utilitarian economics, is based on the central idea that the exchange of social and material resources is a very basic form of human interaction (Ap, 1992). When related to tourism, it views the social interaction between tourists and local residents as a process of negotiation or exchange and considers it as a sequential process, the first stage involving the tourist and the resident being motivated to enter into an exchange (Ap, 1992). For the second stage to be successful, the exchange must be based on fairness, reciprocity, rationality, and satisfactory outcomes. Social exchange theory posits that if the exchange is somewhat unbalanced, or unfair, or benefits do not materialize, then no exchange will occur as the process will be evaluated negatively (Sharpley \& Telfer, 2014). As a case in point, an empirical study used social exchange theory to examine resident reactions to tourism in West Virginia, United States (Gursoy, Jurowski, \& Uysal, 2002). Results showed that the perception of tourism impacts is a result of assessing benefits and costs and that this evaluation is clearly influenced by issues that residents value. Similarly, an empirical study by Jurowski and Gursoy (2004) of residents in Virginia, USA, using social exchange theory, found that residents supported tourism development as it was seen to provide benefits to their community.

Several drawbacks or criticisms of social exchange theory are discussed here. A glaring gap is the lack of cultural context in the norms and rules that regulate social exchange. Social exchange theory is based on the concept of rewards, but cultures are different and in some cultures, its members do not seek a reward for a relationship. The theory is criticized as being too narrow to explain complex social relations (Moscovici, 1981). For example, in the case of Fijian villages, it is considered a duty to commit to village obligations, and no reward is sought when village members are asked by the village headman or turaga ni koro to sit in the community hall and welcome tourists (Cropanzano \& Mitchell, 2005). In addition, the reference to economic models reduce social exchange theory to a set of marketlike exchanges of material objects driven by extrinsic motivations like gain assuming that people are all individualistic - and reward seeking. This may become challenging when applied to the Fijian social context, where the lifestyle is generally a communal and not an individualistic one (Ravuvu, 1983). A major criticism of this theory relates to its lack of theoretical precision, which limits its applicability. There is a lack of information on various exchange rules - for example altruism, group gain, status and competition (Cropanzano \& Mitchell, 2005). Lastly, the theory assumes that human beings act rationally when deciding on an exchange, as per economic 
theory assumptions. This rational behaviour is not always the case, as can be seen from observed daily behaviour.

\section{Social Representations Theory}

According to Moscardo (2009), social representations are "the mental constructs which guide us and define reality" (p. 12). They are both concrete and abstract images and are a means for constructing and understanding social reality. Social representations are influences in a particular society, a set of ideas, values, knowledge, and explanations that comprise a social reality (Moscovici, 1981). As such, social representations theory is closely related to the notion of the social construction of reality, which points out that people's daily realities are maintained through social interactions with family, friends, and strangers (tourists, in this context) (Berger \& Luckmann, 1966). Moscardo (2009) posits in her article that a critical examination of tourism research may be limited by social representations that academic researchers hold. For example, many researchers use the adaptancy platform, which reflects a social representation of tourism as good (Jafari, 1987). Perhaps a possible explanation of this view is that it represents the neoliberal approach associated with the travel industry and the travel interests of the academic researchers themselves, combined with a genuine motivation to seek positive outcomes (Moscardo, 2009). This theoretical platform is similar to attitudes used in psychological studies that exemplify this concept as they arrange information for individuals and assist in directing their actions and evaluations.

Social representations theory was used as a theoretical framework in an empirical study of Australia's Gold Coast Indy Car event, and the study found that, although there is overwhelming support for the event, residents do recognize that there are negative impacts involved as well (Fredline \& Faulkner, 2000). Support for the event comes by way of residents recognizing that the event brings about community selfesteem, business, and employment opportunities, and promotional impacts. However, these Gold Coast residents are also fully aware that the Indy Car event also contributes to increased noise levels, traffic congestion, overcrowding, and lifestyle disruptions (Fredline \& Faulkner, 2000). This empirical study underlines and reaffirms the fundamental concept of social representations theory in its findings. In this particular case, the residents' interpretations of the event are based on their own experiences and backgrounds, and this shapes their reality in relation to the Indy Car event.

Social representations theory has several drawbacks in relation to tourism research. 
Moscovici, the father of social representations theory, based his theory on Durkheim's (1989) notion of collective representations. Durkheim's work presents collective representations as a very general category that includes broad elements like science, ideology, myths, and worldviews. Durkheim does not distinguish between these different forms of organized thought, which leads to a lack of clarity and distinction, or of being too broad and too vague, subsequently one of the weaknesses of Moscovici's theory (Voelklein \& Howarth, 2005). In addition, collective representation does not take into account the mobile and heterogeneous nature of contemporary societies (Howarth, 2001). Another major criticism of social representations theory relates to its overly cognitive phenomenon that does not include adequate reference to social influences (Jahoda, 1988; Semin, 1985). An undue focus on cognitive psychology, and a lack of emphasis on social values, beliefs, and norms leads to the theory becoming overtly focused on the individual (Voelklein \& Howarth, 2005).

\section{Bottom up Spillover Theory}

The basic premise of bottom up spillover theory is that life satisfaction is functionally related to all satisfaction with all of life's domains and sub domains. Life satisfaction is deemed to be on top of a satisfaction ladder. It recognizes that satisfaction with one's life is mostly determined by satisfaction with a variety of life domains. For example, one's overall satisfaction with life is influenced by satisfaction with family, social, leisure, health, work, financial, and travel opportunities (Kruger, 2012). The theory posits that effects within a specific life domain accumulate and vertically spill over to super-ordinate domains (e.g. life in general). It can be said that tourism impacts have an effect on life domain satisfaction, which in turn have an effect on satisfaction with life overall. For example, the more residents perceive economic opportunity from tourism, the more they may feel better about their material wellbeing. Empirical studies that have referenced bottom up spillover theory include Woo, Kim, and Uysal (2015), Kim et al. (2013), and Bimonte and Faralla (2016).

An empirical study undertaken in the Mediterranean town of Follonica utilized the bottom up spillover theory as its major theoretical lens through which to view how residents perceive life satisfaction in relation to tourism. Data analysis showed that residents' happiness was influenced by a wide range of material elements, including material aspects like income and work, but also by non-material aspects, like health, family, friendships, and sentimental situations. This is a crucial aspect that needs to be understood by policy makers and practitioners alike, as hosts are an indispensable part of any sustainable tourism development within any community (Sharpley, 2008). 
The literature reflects that the difference between QOL and attitudes/impacts studies is one that relates to measurement and semantics, given that the studies generally include the same type of measures (Andereck \& Jurowski, 2006) Generally, attitude/impact studies focus on the ways people perceive tourism's influence on communities and the environment, whereas QOL studies deal with the ways that these impacts affect individual or family life satisfaction, including satisfaction with community, neighbourhood, and personal circumstances (Allen, Long, Perdue, \& Kieselbach, 1988). It is assumed that there is a link or connection between community characteristics and life satisfaction. Attitude and impact studies have generally asked residents to agree or disagree with statements in relation to tourism's perceived impacts on their community without specific questions linking these impacts to perceived influences on an individual's life satisfaction or QOL (Andereck et al., 2005).

\section{Sustainable Tourism Attitude Scale (SUS-TAS)}

As discussed earlier in this essay, a variety of theories, measurement tools, and frameworks have been used when measuring residents' QOL impacts resulting from tourism development (Tyrrell, Paris, \& Biaett, 2013). Along with the shift from the narrow focus on mainly economic impacts and the individual, to a communityfocused approach that considers socio-economic wellbeing, is the need for an integrated measurement model. A highly-innovative, empirical study needs to be highlighted here in relation to tourism and quality of life methodology ( $\mathrm{Yu}$, Chancellor, \& Cole, 2011). When surveying 649 residents of Orange County, Indiana, USA on the perceived impacts of tourism on quality of life, a pioneering measurement tool called the Sustainable Tourism Attitude Scale (SUS-TAS model) was utilised. This attitude scale is designed to address the shortcomings of existing models, theories and tools that measure perceptions of positive/negative impacts of tourism. One such model is Lankford and Howard's (1994) Tourism Impact Attitude Scale.

This SUS-TAS model reflects the paradigm shift towards a sustainability platform in QOL measurement categories. The SUS-TAS model aims to capture resident attitudes towards sustainable tourism development by explicitly integrating seven sustainability criteria, namely economic benefits, sociocultural impacts of tourism, community-based benefits, visitor satisfaction, environmental sustainability, long term planning, and community participation. According to Sirakaya-Turk, Ingram, and Harril (2008), the tool not only gauges community sentiments towards sustainable tourism development, but also provides a tool to measure the major 
dimensions of resident quality of life.

\section{Empirical Research}

While it is explicitly understood that tourism provides positive impacts for residents, much less is understood about these types of benefits and costs (Weiermair \& Peters, 2012). The pertinent research question being asked is, "how do tourism activities impact residents' QOL"? In other words, how do tourism activities influence an individual's QOL? Tourism activities are viewed by residents of tourism-active communities as a form of development that positively and negatively influences community quality of life (Andereck \& Nyaupane, 2011; Buzinde et al., 2014; García, Vázquez, \& Macías, 2015; Usher \& Kerstetter, 2014). Once a community becomes "tourism-active", the lives of residents within that community are affected by tourism in many ways (Gursoy et al., 2002). An empirical study that examined the tourism-active community of Las Salinas, Nicaragua found that tourism activities contributed positively to their QOL, which included meaningful employment, preservation of monuments, increased QOL, and preservation of resident identity and cultural pride (Usher \& Kerstetter, 2014). Despite these positive findings, residents lamented about various negative issues that included lack of work, substance abuse, health problems, and environmental degradation.

A similar finding was reported by Andereck and Nyaupane (2011) who found that residents in Arizona perceive both the positive and negative influences of tourism in their communities. Buzinde et al.'s, (2014) empirical research also reaffirms this duality by the acknowledgement that the Masai tribes in Tanzania regarded tourism as a form of development that positively but also negatively influenced their wellbeing. Residents do perceive that tourism activities have a positive influence on their QOL, especially with regard to the availability of recreation amenities and feelings of community pride. They also perceive that tourism positively influences the economy, facilitates the preservation of natural and cultural resources, can enhance community wellbeing, and has an overall positive influence on their way of life. On the other hand, residents also recognize that tourism can have negative QOL consequences, such as more crime and urban issues (Andereck \& Nyaupane, 2011). The Tanzania study also highlights that definitions of QOL must have an emic approach to ensure that cultural differences are taken into account and avoids western characterization of well-being and QOL issues. This is particularly relevant in indigenous communities who have embraced tourism as a tool for economic and social growth or development. 
Resident demographic variables are seen to play a significant role in how QOL was perceived (García et al., 2015). An empirical study undertaken on resident perceptions of tourism development in Spain found that age, marital status, parental status and level of education were strong predictors of positive attitudes towards tourism's impact on the environment, the economy, and socio-cultural life. The study found that its youngest residents, compared to those aged 45-64, were found to have more favourable perceptions of tourism's effects on the local economy. Married residents, compared to unmarried residents, showed more positive attitudes towards overall tourism influences on their QOL.

\section{Beyond Impacts}

An emerging trend that was identified while reviewing research was the move beyond attitude or perceptions research, and the subsequent focus on directly examining individual or resident perceptions of the impact tourism has on their QOL, and relationships between QOL perceptions and support for tourism in the community (Andereck et al., 2011, Andereck et al., 2005). Andereck and Nyaupane's work (2011) that examined residents of Arizona represents this new research trend that goes beyond attitude research and explicitly considers tourism's influence on QOL. The authors suggested a new measurement method for investigating resident perceptions, called the Tourism and Quality of Life Measure. This TQOL measure suggested a subjective approach consistent with that developed in sociology, and they hope that this new TQOL tool will provide a more accurate assessment of the manner in which residents view tourism in their communities, and the way it affects their lives.

Two empirical studies deserve individual attention in relation to our current discussions. The first one concerns an ethnographic case study of Las Salinas, Nicaragua, which looked at understanding resident perceptions of their QOL in the face of tourism development (Usher \& Kerstetter, 2014). It stood out as it looked at a developing country and used an ethnographic approach to its study. Three weeks of participant observation and resident interviews with 27 residents focused on different dimensions of QOL - health, prosperity/jobs, social relations, nature and religion. The results showed that residents were positive in their QOL in the face of tourism development. The positive perception was traced back to two dominant issues: the distance of the tourism development from the city centre of La Salinas; and residents still having control of their communal lands. Quite interestingly, residents were not making the link between environmental degradation and tourism impacts. What the study does is address an existing gap in empirical research using 
an ethnographic approach to assess perceptions of QOL and tourism development, particularly within the space of less-developed countries.

The second empirical study that provides a compelling viewpoint is the study published recently on a rural Masai tribe community in Tanzania (Buzinde et al., 2014). Using a development theory and sustainable tourism approach, the study explored how tourism influences indigenous perceptions of QOL. For the Masai tribe, QOL priorities are children, livestock, and land resources. Money was rated lower as a priority. Tourism development was perceived to have both positive benefits in terms of employment opportunities, the elevation of the status of women while negative impacts centred on land use conflicts and loss of cultural values. Adopting a bottom up approach to examining indigenous conceptions of QOL and to understand how tourism influences indigenous experiences, the paper reflects the need for more dialogue between externally defined measures of QOL and localized conceptions of wellbeing (Buzinde et al., 2014). It reiterates the point made by McCubbin, McCubbin, Zhang, Kehl, \& Strom (2013) that the enhanced understanding and incorporation of indigenous worldviews and knowledge in current indigenous tourism discourse will improve the resilience of these communities. This is not only an ethical imperative but also a pragmatic approach to ensure that the outcomes of academic research facilitate the sustainability of indigenous tourism (Whitford \& Ruhanen, 2016).

\section{Small Island Destinations}

Lately, several case studies have highlighted or focused on small island destinations engaged with tourism development, including Aruba in the Caribbean (Croes et al., 2011); Cyprus in the Mediterranean; Mauritius in the Indian Ocean (Sharpley \& Naidoo, 2010); Fiji in the Pacific Ocean (Pratt, McCabe, \& Movono, 2016); Sitka in Alaska (Vogt, Jordan, Grewe, \& Kruger, 2016); and Magnetic Island in Australia (Pearce et al., 1996). A major theoretical proposition gleaned from the above island case studies is that the relationship between income and happiness of residents in small island destinations is not self-evident. This argument backs up existing evidence in the happiness literature and points to other factors that may be at play in influencing the nature of the relationship between income and happiness. In essence, while tourism development may provide income to households in small island destinations, resident wellbeing is not necessarily improved. Therefore, income may not be an adequate substitution for wellbeing and instead may be insufficient to understand resident wellbeing - in this case transcending culture, history and political status. 


\section{Pacific Indigenous Communities}

A body of literature has recently emerged on indigenous communities and their tourism and QOL dynamics. Highlighting indigenous worldviews on tourism impacts on their QOL, studies were conducted -- for example, in Tonga (Dyall et al., 1999), Australia (Greiner, Larson, Herr, \& Bligh, 2005), Mauritius (Sharpley \& Naidoo, 2010), Aruba (Croes et al., 2011), Hawaii (McCubbin et al., 2013), Tanzania (Buzinde et al., 2014), Nicaragua (Usher \& Kerstetter, 2014), and Alaska (Vogt, Jordan, Grewe, \& Kruger, 2016). The above-mentioned studies reflect significant similarities, as well as differences, which focus on the social, cultural and psychological needs of people, their families, institutions and communities in order to understand the various elements that impact well-being or QOL. The notion of family and community resonates deeply and widely among the majority of the studies mentioned above. The Australian study of the Nywaigi traditional owners cites family and community as priority in their QOL, followed by health and health services (Greiner et al., 2005). Similarly, a study on native Hawaiians (based on 2008 Hawaii Health Survey Data) suggested that Hawaiians valued family commitment and involvement and contribution to one's community as highly valued in their construct of QOL. The above studies also suggest that extant measures of QOL, which are guided by European values and beliefs, are limiting, and alternative conceptualizations need to be considered to accommodate indigenous worldviews (McCubbins et al., 2013).

South Pacific research suggests that, while most of the earlier work focused on underdevelopment perspectives of tourism (Britton, 1982; Racule, 1995; Varley, 1978), more recent work has emerged in relation to tourism impacts and quality of life of communities, predominantly in Fiji (Kerstetter \& Bricker, 2009; King, Pizam, \& Milman, 1993; Pratt et al., 2016; Movono \& Becken, 2018; Matatolu, 2018). Britton's (1982) ground breaking work on Fiji tourism deserves special mention as it frames the scope of tourism development discussions within the South Pacific context, which certainly influences contemporary tourism and quality of life. Of particular importance is his quote below:

When a third world country uses tourism as a development strategy, it becomes entrenched in a global system over which it has little control... the international tourism industry is a product of metropolitan capitalist enterprise.... the industry, because of the commercial power held by foreign enterprise, imposes on peripheral destinations a development mode which reinforces dependency on, and vulnerability to, developed 
countries. (Britton, 1982 p. 22).

We now focus on recent studies undertaken in the South Pacific region on this area of tourism research. A recent case study of Sautabu village residents' perceptions of tourism and its impacts on their QOL undertaken by Matatolu (2018) highlighted that the residents' QOL priorities are culturally informed or closely mirror their cultural values. Sautabu residents highlighted the land (vanua), family (vuvale) and faith (lotu) as key priorities in their QOL. The Vanua, which is at the heart of being Fijian, refers to the interconnectedness of Fijians to their land, environment, culture, relationships, spirit world, beliefs, knowledge systems, values, and God/s. (NaboboBaba, 2006). Respondents' statements included, "without the vanua, we are nothing"; "our land will always continue to be an important part of our identity as indigenous Fijians" (Matatolu, 2018, p. 72). Within the context of indigenous Fijian communities, land becomes more than a physical commodity as normally seen through the western gaze. Often these go into spiritual dimensions and residents may choose not to share spiritual insights with visitors or they may restrict certain areas in the village that are considered sacred (Hollinshead, 1996). The Sautabu tour guide shared that tourists who visit Sautabu village are not allowed to go into the chief's bure or the burial grounds, as this is considered sacred by the villagers (Matatolu, 2018).

Movono and Becken (2018) explored how tourism development has impacted a Fijian village's development pathway, and explored how preferential access to tourism benefits has created disparities among residents of the community. The study found that tourism contributed to new behaviours and new ways of life, leading to the collapse of pre-existing systems of social capital. Showing community resilience, residents retreated and regrouped and formed smaller social groups and strengthened their social bonds. Pratt et al.'s (2016) study looked at how tourism contributed to holistic QOL by studying two Fijian villages - one with a high dependency on tourism income and the second considered untouched by tourism or zero benefit from tourism development. This study assessed whether tourism contributes to holistic QOL, or simply phrased in question format, "does tourism make people happy?" Using an adapted version of the Bhutan Gross Happiness Index, the study compared the level of wellbeing of these villages in relation to tourism's contribution to overall QOL. The Gross Happiness Index is a tool to assess the overall happiness of a community or country. Nine key dimensions are used: psychological wellbeing, time use, community vitality, cultural diversity, ecological resilience, living standards, health, education, and good governance. Results showed that despite the tourismdependent village being materially wealthier, the non-tourism village residents were 
generally happier across a number of life domains. These domains included health, cultural diversity and resilience, good governance, community vitality, and ecological diversity and resilience.

Even though the tourism-villagers benefited financially from tourism in terms of jobs and income, the non-tourism villagers believed they were wealthier in terms of kinship and traditional ties and fewer concerns about money and material wealth. Another possible reason for the more positive response from the non-tourism village could be explained by cultural nuances. Fijians, out of their perceived obligation to please, will be inclined to tell you the more positive responses first, so researchers need to spend more time and dig deeper. Given the fact that this particular example was a case study, the question of how representative this study is to other villages across Fiji remains in question. This paper suggests that more research on villages with varying levels of exposure to tourism can address this criticism. In addition to studying residents, surveying workers in the tourism and hospitality industry would provide rich data to add to the depth and scope of research quality in indigenous community spaces. These innovative studies point to the critical importance of issues that must be considered by policy makers and practitioners in the development of sustainable tourism development policies and plans in small island developing spaces in the South Pacific.

A contemporary empirical research study undertaken in Fiji and using innovative methodology in relation to host perceptions of tourism and QOL also needs to be highlighted here. Kerstetter and Bricker (2009) undertook empirical research in one of Fiji's most remote and less developed tourism archipelagos, the Yasawa Islands. These remote islands face many challenges in economic development and in the last two decades have seen a growth in backpacker type tourism. This growth is partly the result of the Ministry of Tourism's efforts to increase visitor arrivals into Fiji (Fiji Visitors Bureau, 2006). Today there are nearly 40 resorts in the Yasawas, with most directly linked to villages or community-based. This means these resorts are managed and maintained by these communities (Gibson, 2012). The Yasawas now host more than 545,000 visitors per year (Ministry of Tourism IVS Report, 2014). This growth has not come without its challenges. Pressure on freshwater supply, lack of sewage treatment facilities, no coordinated solid waste management program, unlicensed properties, and social tension among community members are key issues facing this tourism region in Fiji.

These issues certainly impact the QOL of these communities in many ways. Using photo elicitation as a methodology to give voice or attach meanings to their places, 
the researchers found results quite distinct from similar research in western spaces. They found that residents value the Fijian way of life, the culture, the vanua and its traditions. Vanua is a distinct phenomenon in the Fijian context, where it describes a Fijian's connection with their environment. It does not only mean land but also refers to its social and cultural systems - the people, their traditions, their beliefs, values, customs, and institutions that play a role in achieving harmony and solidarity within their social context (Ravuvu, 1983). Residents also placed a high value on environmental protection, which they saw as central to both their QOL and also tourism. These meanings comprised major aspects of tourism development, including economic benefits, sociocultural benefits, environmental benefits, tourism accommodation, and facilities. These highlighted issues are important considerations for tourism planners and marketers in Fiji, as they represent critical issues that are important for residents' QOL who reside in tourism regions in Fiji (Kerstetter \& Bricker, 2009). It can be argued that these provide an interesting departure to extant QOL literature, which highlights predominantly western characterization of wellbeing with values like money, income and material wealth considered of paramount importance in western spaces (Kim, et al., 2013).

\section{Key Gaps}

Given the scope and range of empirical research discussed above, we now highlight key gaps. The majority of the empirical research is situated within developed countries and there is a need to push for similar studies in developing countries and small island spaces, as these spaces have embraced tourism development as an engine of economic growth for their economies (Sharpley \& Telfer, 2014). It is no coincidence that in 2014 the top ten countries in which tourism contributed relatively most to GDP were all islands (World Travel and Tourism Council, 2015). Little attention has been made specifically to the implications of tourism development for the wellbeing of the residents of small island states, including the South Pacific region. In addition to being rare, these studies have also neglected to review the types of tourism that are frequently typified in these spaces, such as resort-based tourism, or enclave tourism (Sharpley \& Naidoo, 2010).

\section{Cross Cultural Studies}

There is also a need to develop cross-cultural QOL studies as most communities that embrace tourism now are comprised of diverse cultures, including indigenous and minority cultures, as all relevant groups within a community must have a voice (Andereck \& Jurowski, 2006). Effects of tourism development and seasonality may 
be different for different types of people (Butler, 1980). In addition, such crosscultural studies must be in a position to use bi-lingual survey instruments to be able to capture the required depth of understanding required from these qualitative-driven studies (Andereck \& Jurowski, 2006). This is especially true of communities for which English is not their mother-tongue or first language.

\section{Ethnographic Studies}

Lastly, there is a critical gap in using an ethnographic approach to assess QOL perceptions and tourism development, particularly within Less Developed Countries (LDCs). Moscardo (2009) believed that lack of understanding of tourism impacts is a factor for underdevelopment of tourism in third world countries. The case study undertaken by Usher and Kerstetter (2014) of the Las Salinas community in Nicaragua was a classic and rare case of ethnography being used to examine resident perceptions of QOL in relation to tourism development. By living among residents for three weeks and developing a rapport with them, the authors were able to delve deeper and obtained a profound understanding of resident perceptions of QOL. They learned about the importance of jobs, the perceived role of government in QOL, poverty and the need for foreign aid, the impact of social ills like drugs and alcohol, health issues, the importance of family and community, and the role of the environment in resident views of QOL (Usher and Kerstetter, 2014).

\section{Universal Definition Lacking}

In addition to the above gaps, a lack of an agreed universal definition of QOL lends itself to many challenges in terms of definitions. QOL is not exactly the same as material well-being or standard of living, nor can it be the same as life expectancy, infant mortality, or literacy rates. QOL also has subjective components like happiness, life satisfaction, and recreation opportunities (Lankford \& Howard, 1994). It is therefore imperative that future research on resident perceptions and QOL focus both on the objective and subjective components to be able to capture a more allencompassing and inclusive assessment and measurement of QOL. Resident characteristics should also be considered when undertaking QOL and tourism impacts research. For example, if residents work in the tourism and hospitality industry, they are more likely to positively perceive the impact of tourism as compared to community residents who come from an agricultural-based economy. It is critical that this gap be addressed by future research. Similarly, the scope of perceived value in terms of measurement should be expanded to include functional, social, cultural, emotional and economic value when measuring the perceived value 
of tourism development (Woo et al., 2015).

\section{Future Direction}

While the global focus of rising overtourism makes it imperative for tourism research to focus on the quality of life of local residents and how it is impacted by tourism, it is noted that there are several limitations of this current research area. The majority of the research undertaken so far has been done in the form of surveys in settings that vary widely in terms of the nature, scale, and stage of tourism development (Andereck \& Jurowski, 2006). They also make a point of stating that even when a similar survey methodology is used, results are widely varied. It is also highlighted that most empirical research undertaken is quantitative in nature and there is a subsequent need for more qualitative methods of study to be applied in this research field to ensure that these studies maximize their opportunity to contribute to knowledge long term (Andereck \& Jurowski, 2006; Deery, Jago, \& Fredline, 2012). Interdisciplinary research in QOL studies is also needed within managerial (policy), behavioural, social, medical, environmental, psychological, and social sciences to enhance the development of knowledge in this critical area. In addition, studies are done in settings where tourism is embedded within the communities, so it's difficult to isolate tourism's effects from other wealth-creating activities, such as agriculture (Croes, 2012).

There is also a discrepancy in terms of the location or settings of these empirical studies. While dominated by studies in developed countries (Andereck et al., 2005; Andereck \& Nyaupane, 2011; Carmichael, 2000; Lankford \& Howard, 1994), very little work has been done in small-island destination spaces, including the South Pacific region (Bastias-Perez \& Var, 1995; Gursoy, Chi, \& Dyer, 2009). There is also a need to generate more studies with an ethnographic approach, so that a deeper understanding of the key issues is obtained (Andereck \& Jurowski, 2006). In addition, there is a dire need to carry out research among indigenous communities and delve deeper into their social and cultural fabric so that the generalizability of findings can be improved (Sirgy et al., 2010). There is also a need to find a consensus in terms of definitions of key terms like QOL and measurement domains within this academic research space for obvious reasons (Andereck \& Jurowski, 2006).

Any future research undertaken on the topic of tourism impacts and QOL needs to address the obvious need for a consensus in terms of definitions for QOL, as this will provide the much needed scope and direction within this field (Andereck et al., 2005; Sirgy et al., 2010). Tourists and community residents view or see life through 
different gazes, so life domains that are important for tourists will be quite different for community residents. This was brought home very clearly in the empirical study undertaken in Tanzania, where livestock, children and land resources were rated much higher than money (Buzinde et al., 2014). Therefore, it is evident that life domains vary across communities, cultures and contexts. This major area needs to be addressed by future research in terms of the measurement and definitions of life domains. Any future research must also be carried out using different levels of analysis. These different levels include individual, family, community and country levels of analysis (Sirgy, Efraty, Siegel, \& Lee, 2001).

Future research should also look at creating life domains by population group and settings. Tourists experiencing wildlife tourism may have different life domain perspectives to tourists on a cruise experience. Medical tourists may consider health life domain as critically important, while adventure tourists may consider leisure life domain as very important (Uysal et al., 2016). Kara, Kim and Uysal (2018) also point out that there is a need to carry out QOL research for employees in the tourism industry, as most of the research has been focused on community residents. A further exploration of QOL constructs in terms of outcomes and variables, along with support for tourism development as a dependent variable (Uysal et al., 2016), is needed as well. Finally, it is generally acknowledged that there should be an inclusion of longitudinal studies as most of the research reviewed earlier focused on the examination of tourism and its impacts on residents' QOL at one point in time. It is critical to develop longitudinal studies that generate data at different points in time for obvious reasons.

\section{Indigenous communities}

Research on indigenous communities must also take centre stage as indigenous people and indigenous tourism is now a major part of global tourism's fabric. The demand for indigenous tourism products has led to increased contact between nonindigenous people and indigenous communities, driving winds of change in the QOL of these communities. Perhaps the key issue is to ensure that the indigenous hosts play a greater role in controlling and directing the pace and nature of this contact. What is critically needed is the indigenous researcher's voice to be heard to not only balance the non-indigenous voice, but provide a more accurate range of cultural perspectives. Smith (1999) speaks to the process as one that involves the decolonization of methodologies where western ethnocentric views are replaced by the evolving indigenous research agenda (Smith, 1999). 


\section{Conclusion}

In summary, research on tourism and resident QOL shows that once a community becomes a tourist place or destination, the lives of the residents or "hosts" are affected at various levels, so the support of the hosts is critical for the sustainability of the tourism development (Jurowski, Uysal, \& Williams, 1997). Therefore, the QOL of residents should be a major concern for all stakeholders. A universally applicable definition of QOL that covers major life satisfaction domains over and above the predominantly economic domains is needed. This is particularly important for the need to reflect the interdependent relationship between community QOL and the well-known pillars of sustainability: environmental quality, economic prosperity, and social wellbeing (Rogers \& Ryan, 2001). There is also a need for an integrated assessment tool of the impacts of tourism on communities' QOL that includes the cultural values of a community, measures the performance of the tourism industry, and provides concise information that allows decision makers to make informed decisions about tourism within the greater tourism system (Olsen, Canan, \& Hennessy, 1985). More research is also needed in cross-cultural communities, in particular indigenous communities that have embraced tourism as a tool for economic growth. Indigenous communities present a complex interplay of cultures and their unique relationship with the land presents a rich field for research and scholarship within the tourism academy.

\section{References}

Allen, L. R., Long, P. T., Perdue, R. R., \& Kieselbach, S. (1988). The impact of tourism development on residents' perceptions of community life. Journal of Travel Research, 27(1), 16-21.

Andereck, K., \& Vogt, C. A. (2000). The relationship between residents' attitudes toward tourism and tourism development options. Journal of Travel Research, 39(1), 27-36.

Andereck, K., Valentine, K., Knopf, R., \& Vogt, C. (2005). Residents' perceptions of community tourism impacts. Annals of Tourism Research, 32(4), 10561076 .

Andereck, K., \& Jurowski, C. (2006). Tourism and quality of life. Quality Tourism Experiences, 136-154. 
Andereck, K. L., \& Nyaupane, G. (2011). Development of a tourism and quality-oflife instrument. In M. Budruk \& R. Phillips (Eds.), Quality-of-life community indicators for parks, recreation and tourism management (pp. 95-113). Dordrecht, Netherlands: Springer.

Andriotis, K., \& Vaughan, R. D. (2003). Urban residents' attitudes toward tourism development: The case of Crete. Journal of Travel Research, 42(2), 172-185.

Ap, J. (1992). Residents' perceptions on tourism impacts. Annals of Tourism Research, 19(4), 665-690.

Ap, J., \& Crompton, J. L. (1993). Residents' strategies for responding to tourism impacts. Journal of Travel Research, 32(1), 47-50.

Aref, F. (2010). Residents' attitudes towards tourism impacts: A case study of Shiraz, Iran. Tourism Analysis, 15(2), 253-261.

Ateljevic, I., Hollinshead, K., \& Ali, N. (2009). Special issue endnote: Tourism and worldmaking-where do we go from here? Tourism Geographies, 11(4), 546552.

Babbie, E. R. (1998). The practice of social research (8th ed.). Belmont, CA: Wadsworth..

Bastias-Perez, P., \& Var, T. (1995). Perceived impacts of tourism by residents. Annals of Tourism Research, 22(1), 208-210.

Belisle, F. J., \& Hoy, D. R. (1980). The perceived impact of tourism by residents a case study in Santa Marta, Colombia. Annals of Tourism Research, 7(1), 83101.

Berger, P. L., \& Luckmann, T. (1966). The social construct of reality. City, NY: Name of Publisher.

Bimonte, S., \& Faralla, V. (2016). Does residents' perceived life satisfaction vary with tourist season? A two-step survey in a Mediterranean destination. Tourism Management, 55, 199-208.

Bonner, A., \& Tolhurst, G. (2002). Insider-outsider perspectives of participant observation. Nurse Researcher, 9(4), 7-19. 
Boukas, N., \& Ziakas, V. (2013). Impacts of the global economic crisis on Cyprus tourism and policy responses. International Journal of Tourism Research, 15(4), 329-345.

Britton, S. G. (1982). The political economy of tourism in the Third World. Annals of Tourism Research, 9(3), 331-358.

Butler, R. W. (1980). The concept of a tourist area cycle of evolution: Implications for management of resources. The Canadian Geographer/Le Géographe canadien, 24(1), 5-12.

Buzinde, C. N., Kalavar, J. M., \& Melubo, K. (2014). Tourism and community wellbeing: The case of the Maasai in Tanzania. Annals of Tourism Research, 44, 20-35.

Campbell, A. (1974). Quality of life as a psychological phenomenon. Subjective elements of well-being, 9-19.

Carmichael, B. A. (2000). A matrix model for resident attitudes and behaviours in a rapidly changing tourist area. Tourism Management, 21(6), 601-611.

Cecil, A. K., Fu, Y.-Y., Wang, S., \& Avgoustis, S. (2010). Cultural tourism and quality of life: Results of a longitudinal study. European Journal of Tourism Research, 3(1), 54.

Choi, H. C., \& Sirakaya, E. (2006). Sustainability indicators for managing community tourism. Tourism Management, 27(6), 1274-1289.

Constanza, R., Fisher, B., Ali, S., Beer, C., Bond, L., Boumans, R., . . Farley, J. (2008). An integrative approach to quality of life measurement. Research, and Policy.[Online], 1.

Creswell, J. W. (2009). Research design: Qualitative and mixed methods approaches. London and Thousand Oaks, United Kingdom: Sage Publications.

Croes, R. (2012). Tourism, poverty relief, and the quality-of-life in developing countries. In M. Uysal, R. Perdue, \& M. J. Sirgy (Eds.), Handbook of Tourism and Quality-of-Life Research (pp. 85-103). Dordrecht, Netherlands: Springer. 
Croes, R. R., Rivera, M. A., Pizam, A., Olson, E. D., Lee, S. H., \& Zhong, Y. Y. (2011). Winning the future: Strategic Plan for the development of Tourism.

Cropanzano, R., \& Mitchell, M. S. (2005). Social exchange theory: An interdisciplinary review. Journal of Management, 31(6), 874-900.

Crystal, E. (1989). Tourism in Toraja (Sulawesi, Indonesia). In V. Smith (Ed.), Hosts and guests: The anthropology of tourism (2nd ed.) (pp. 139-168). Philadelphia, PA: University of Pennsylvania Press.

Cummins, R. A. (1997). Assessing quality of life. In R. Brown (Ed.), Quality of life for people with disabilities: Models, research and practice (2nd ed.) (pp. 116150). Cheltenham, UK: Stanley Thornes Ltd.

Deery, M., Jago, L., \& Fredline, L. (2012). Rethinking social impacts of tourism research: A new research agenda. Tourism Management, 33(1), 64-73.

Denzin, N. K. (1978). The research act: A theoretical orientation to sociological methods. McGraw-Hill, New York._2012,'Triangulation, 2, 80-88.

Diener, E., \& Lucas, R. E. (1999). 11 Personality and Subjective Well-Being. Wellbeing: Foundations of hedonic psychology, 213.

Douglas, J. D. (1985). Creative interviewing. Beverly Hills, CA: Sage.

Doxey, G. V. (1975, September). A causation theory of visitor-resident irritants: Methodology and research inferences. In Travel and tourism research associations sixth annual conference proceedings (pp. 195-98).

Dwyer, S. C., \& Buckle, J. L. (2009). The space between: On being an insideroutsider in qualitative research. International Journal of Qualitative Methods, $8(1), 54-63$.

Dyall, L., Bridgman, G., Bidois, A., Gurney, H., Hawira, J., Tangitu, P., \& Huata, W. (1999). Māori outcomes: Expectations of mental health services. Social Policy Journal of New Zealand, 12, 71-90.

Easterlin, R. A. (2003). Explaining happiness. Proceedings of the National Academy of Sciences, 100(19), 11176-11183. 
Ereaut, G. (2002). Analysis and interpretation in qualitative market research (Vol. 4): Sage Publications

Fiji Visitors Bureau. (2006). Realizing the industry's potential through responsible tourism: 2006 Fiji Visitors Bureau marketing plan. Nadi, Fiji: Fiji Visitors Bureau.

Fredline, E., \& Faulkner, B. (2000). Host community reactions: A cluster analysis. Annals of Tourism Research, 27(3), 763-784.

García, F. A., Vázquez, A. B., \& Macías, R. C. (2015). Resident's attitudes towards the impacts of tourism. Tourism Management Perspectives, 13, 33-40.

Geertz, C. (1973). The interpretation of cultures: Selected essays (Vol. 5019): Basic books.

Gibbs, G. R. (2007). Thematic coding and categorizing. Analyzing qualitative data. London: Sage, 38-56.

Gibson, D. (2012). The cultural challenges faced by indigenous-owned small medium tourism enterprises (SMTEs) in Fiji: Case studies from the Yasawa Islands. The Journal of Pacific Studies, 32(2), 102-126.

Graham, H. (1984). Surveying through stories. Social researching: Politics, problems, practice, 104-124.

Grasswick, H. (2008). Feminist social epistemology.

Greiner, R., Larson, S., Herr, A., \& Bligh, V. (2005). Wellbeing of Nywaigi traditional owners: The contribution of country to wellbeing and the role of natural resource management, Report for Burdekin dry Tropics Board, Townsville. Townsville CSIRO Sustainable Ecosystems.

Gursoy, D., Ouyang, Z., Nunkoo, R., \& Wei, W. (2019). Residents' impact perceptions of and attitudes towards tourism development: A metaanalysis. Journal of Hospitality Marketing \& Management, 28(3), 306-333.

Gursoy, D., Chi, C. G., \& Dyer, P. (2009). Locals' attitudes toward mass and alternative tourism: the case of Sunshine Coast, Australia. Journal of travel research. 
Gursoy, D., Jurowski, C., \& Uysal, M. (2002). Resident attitudes: A structural modeling approach. Annals of Tourism Research, 29(1), 79-105.

Hagerty, M. R., Cummins, R. A., Ferriss, A. L., Land, K., Michalos, A. C., Peterson, M., . . Vogel, J. (2001). Quality of life indexes for national policy: Review and agenda for research. Social Indicators Research, 55(1), 1-96.

Hammersley, M., \& Atkinson, P. (2007). Ethnography: Principles in practice: Routledge Press. London

Harding, S. G. (1986). The science question in feminism. Ithaca, NY: Cornell University Press.

Hinch, T. D. (2004). Indigenous people and tourism. A companion to tourism, 246257.

Hollinshead, K. (1996). The tourism researcher as bricoleur: the new wealth and diversity in qualitative inquiry. Tourism Analysis, 1(1), 67-74.

Hollinshead, K. (2007). Worldmaking'and the transformation of place and culture: The enlargement of Meethan's analysis of tourism and global change. The critical turn in tourism studies: Innovative research methodologies, 165-193. Wrong

Howarth, C. S. (2001). Towards a social psychology of community: A social representations perspective. Journal for the Theory of Social Behaviour, $31(2), 223-238$.

Hughes, M., \& Hertel, B. R. (1990). The significance of color remains: A study of life chances, mate selection, and ethnic consciousness among Black Americans. Social Forces, 68(4), 1105-1120.

Ingersoll-Dayton, B., Saengtienchai, C., Kespichayawattana, J., \& Aungsuroch, Y. (2004). Measuring psychological well-being: Insights from Thai elders. The Gerontologist, 44(5), 596-604.

Jafari, J. (1987). Tourism models: The sociocultural aspects. Tourism Management, $8(2), 151-159$.

Jahoda, G. (1988). Critical notes and reflections on 'social representations'. European journal of social psychology, 18(3), 195-209. 
Jurowski, C., \& Brown, D. O. (2001). A comparison of the views of involved versus noninvolved citizens on quality of life and tourism development issues. Journal of Hospitality \& Tourism Research, 25(4), 355-370.

Jurowski, C., \& Gursoy, D. (2004). Distance effects on resident's attitudes towards tourism. Annals of Tourism Research, 31(2), 296-312.

Jurowski, C., Uysal, M., \& Williams, D. R. (1997). A theoretical analysis of host community resident reactions to tourism. Journal of travel research, 36(2), 3-11.

Kara, D., Kim, H., \& Uysal, M. (2018). The effect of manager mobbing behaviour on female employees' quality of life. Current Issues in Tourism, 21(13), 1453-1467.

Kerstetter, D., \& Bricker, K. (2009). Exploring Fijian's sense of place after exposure to tourism development. Journal of Sustainable Tourism, 17(6), 691-708.

Kerstetter, K. (2012). Insider, Outsider, or somewhere in between: The impact of researcher's identities on the community-based research process. Journal of Rural Social Sciences, 27(2), 99.

Khizindar, T. M. (2012). Effects of tourism on residents' quality of life in Saudi Arabia: An empirical study. Journal of Hospitality Marketing \& Management, 21(6), 617-637.

Kim, K. (2002). The effects of tourism impacts upon quality of life of residents in the community (Doctoral dissertation, Virginia Tech).

Kim, H., Woo, E., \& Uysal, M. (2015). Tourism experience and quality of life among elderly tourists. Tourism Management, 46, 465-476.

Kim, K., Uysal, M., \& Sirgy, M. J. (2013). How does tourism in a community impact the quality of life of community residents? Tourism Management, 36, 527540 .

King, B., Pizam, A., \& Milman, A. (1993). Social impacts of tourism: Host perceptions. Annals of Tourism Research, 20(4), 650-665.

Kitzinger, J. (1995). Qualitative research. Introducing focus groups. BMJ: British Medical Journal, 311(7000), 299. 
Krippendorff, K. (2004). Content analysis: An introduction to its methodology: Sage Publications. Thousand Oaks.

Kruger, P. S. S. (2012). Perceptions of tourism impacts and satisfaction with particular life domains. In Handbook of tourism and quality-of-life research (pp. 279-292). Springer, Dordrecht.

Kusel, J., \& Fortmann, L. (1991). Well-being in forest-dependent communities (Vol. 1): Forest and Rangeland Resources Assessment Program

Lankford, S. V., \& Howard, D. R. (1994). Developing a tourism impact attitude scale. Annals of Tourism Research, 21(1), 121-139.

Lepp, A. (2007). Residents' attitudes towards tourism in Bigodi village, Uganda. Tourism Management, 28(3), 876-885.

Liu, J. C., \& Var, T. (1986). Resident attitudes toward tourism impacts in Hawaii. Annals of Tourism Research, 13(2), 193-214.

Louis, M. R., \& Bartunek, J. M. (1992). Insider/outsider research teams: Collaboration across diverse perspectives. Journal of Management Inquiry, 1(2), 101-110.

Lundberg, D. E. (1980). The tourist business: CBI Publishing Incorporation.

Lloyd, K., \& Little, D. E. (2005). "Quality of life, aren't we always searching for that?": How women can achieve enhanced quality of life through participation in outdoor adventure recreation. Leisure/Loisir, 29(2), 147-181.

Ma, S. C., \& Kaplanidou, K. (2017). Legacy perceptions among host Tour de Taiwan residents: The mediating effect of quality of life. Leisure Studies, 36(3), 423437.

MacCannell, D. (1976). The tourist: A new theory of the leisure class: Univ of California Press. Thousand Oaks.

Markwell, K., \& Basche, C. (1998). Using personal diaries to collect data. Annals of Tourism Research, 25(1), 228-231.

Marshall, C., \& Rossman, G. (1989). B.(1999). Designing qualitative research. Newbury Park/London/New Delhi. 
Massam, B. H. (2002). Quality of life: Public planning and private living. Progress in Planning, 58(3), 141-227.

Matatolu, I. (2018) Tourism and quality of life in the Fiji Islands: A case study of a rural Fijian village (Unpublished Masters thesis). University of the South Pacific, Fiji.

McCabe, S., \& Johnson, S. (2013). The happiness factor in tourism: Subjective wellbeing and social tourism. Annals of Tourism Research, 41, 42-65.

McCaslin, M. L., \& Scott, K. W. (2003). The five-question method for framing a qualitative research study. The Qualitative Report, 8(3), 447-461.

McCubbin, L. D., McCubbin, H. I., Zhang, W., Kehl, L., \& Strom, I. (2013). Relational well-being: An indigenous perspective and measure. Family Relations, 62(2), 354-365.

McFall-McCaffery, J. (2010). Getting started with Pacific research: Finding resources and information on Pacific research models and methodologies. Mai Review, 1, 1-5.

Meng, F., Li, X., \& Uysal, M. (2010). Tourism development and regional quality of life: The case of China. Journal of China Tourism Research, 6(2), 164-182.

Mercer, J. (2007). The challenges of insider research in educational institutions: Wielding a double-edged sword and resolving delicate dilemmas. Oxford Review of Education, 33(1), 1-17.

Merton, R. K. (1972). Insiders and outsiders: A chapter in the sociology of knowledge. American journal of Sociology, 78(1), 9-47.

Movono, A., \& Becken, S. (2018). Solesolevaki as social capital: A tale of a village, two tribes, and a resort in Fiji. Asia Pacific Journal of Tourism Research, 23(2), 146-157.

Morgan, D. L., \& Krueger, R. A. (1998). Planning focus groups (Vol. 2): Sage Publications London

Moscardo, G. (2009). Tourism and quality of life: Towards a more critical approach. Tourism and Hospitality Research, 9(2), 159-170. 
Moscovici, S. (1981). On social representations. Social cognition: Perspectives on everyday understanding, 8(12), 181-209.

Nabobo-Baba, U. (2006). Knowing and learning: An indigenous Fijian approach: University of the South Pacific. Institute of Pacific Studies, Suva.

Nayacakalou, R. R. (1975). Leadership in Fiji: Oxford University Press. Melbourne

Nunkoo, R., Smith, S. L., \& Ramkissoon, H. (2013). Residents' attitudes to tourism: A longitudinal study of 140 articles from 1984 to 2010. Journal of Sustainable Tourism, 21(1), 5-25.

OECD - Organisation for Economic Cooperation and Development (2007) Glossary of statistical terms. Retrieved from https://ec.europa.eu/eurostat/ramon/coded_files/OECD_glossary_stat_terms. pdf

Olsen, M. E., Canan, P., \& Hennessy, M. (1985). A value-based community assessment process: Integrating quality of life and social impact studies. Sociological Methods \& Research, 13(3), 325-361.

Orange, L. M. (1995). Skills development for multicultural rehabilitation counseling: A quality of life perspective. Disability and Diversity: New leadership for a new era, 68-74.

Ouyang, Z., Gursoy, D., \& Chen, K. C. (2019). It's all about life: Exploring the role of residents' quality of life perceptions on attitudes toward a recurring hallmark event over time. Tourism Management, 75, 99-111.

Pearce, P. L., Moscardo, G., \& Ross, G. F. (1996). Tourism community relationships. Oxford, UK: Pergamon Oxford.

Perdue, R. R., \& Gustke, L. (1991). The effects of tourism development on objective indicators of local quality of life. Paper presented at the Tourism: building credibility for a credible industry. Proceedings of the Travel and Tourism Research Association twenty-second annual conference, Hyatt Regency Hotel, Long Beach, California, June 9-13, 1991.

Perdue, R. R., Long, P. T., \& Allen, L. (1990). Resident support for tourism development. Annals of Tourism Research, 17(4), 586-599. 
Pizam, A. (1978). Tourism's impacts: The social costs to the destination community as perceived by its residents. Journal of travel research, 16(4), 8-12.

Pratt, S., Gibson, D., \& Movono, A. (2013). Tribal tourism in Fiji: An application and extension of Smith's 4Hs of indigenous tourism. Asia Pacific Journal of Tourism Research, 18(8), 894-912.

Pratt, S., McCabe, S., \& Movono, A. (2016). Gross happiness of a'tourism'village in Fiji. Journal of Destination Marketing \& Management, 5(1), 26-35.

Prentice, R. (1993). Community-driven tourism planning and residents' preferences. Tourism Management, 14(3), 218-227.

Pukeliene, V., \& Starkauskiene, V. (2011). Quality of life: Factors determining its measurement complexity. Engineering Economics, 22(2), 147-156.

Racule, A. (1995). The impact of tourism on Fijian culture: Pacific Manuscripts Bureau, Australian National University. Canberra

Rallis, S. F., \& Rossman, G. B. (1998). Learning in the field: An introduction to qualitative research. Sage Productions Thousand Oaks.

Rapley, M. (2003). Quality of life research: A critical introduction: Sage Publications. Thousand Oaks.

Ravuvu, A. (1983). Vaka i Taukei: The Fijian way of life: Institute of Pacific Studies of the University of the South Pacific. Suva.

Renner, M., \& Taylor-Powell, E. (2003). Analyzing qualitative data. Programme Development \& Evaluation, University of Wisconsin-Extension Cooperative Extension.

Richards, G., \& Hall, D. (2003). Tourism and sustainable community development (Vol. 7): Psychology Press.London

.Rogers, M., \& Ryan, R. (2001). The triple bottom line for sustainable community development. Local Environment, 6(3), 279-289.

Rossi, R. J., \& Gilmartin, K. J. (1980). The handbook of social indicators: sources, characteristics, and analysis: Garland STPM New York. 
Saxena, S., Orley, J., \& WHOQOL Group. (1997). Quality of life assessment: the World Health Organization perspective. European Psychiatry, 12, 263s266s.

Scheyvens, R. (2007). Exploring the tourism-poverty nexus. Current Issues in Tourism, 10(2-3), 231-254.

Schuessler, K. F., \& Fisher, G. A. (1985). Quality of life research and sociology. Annual Review of Sociology, 129-149.

Schutz, A. (1964). Collected papers, vol. II. Studies in social theory.

Semin, G. (1985). The 'phenomenon of social representations': A comment on Potter \& Litton. British Journal of Social Psychology, 24(2), 93-94.

Sen, A. K. (1992). Inequality reexamined. Oxford University Press.

Sharpley, R. (2008). Tourism, tourists and society: Elm publications.Wrong

Sharpley, R. (2014). Host perceptions of tourism: A review of the research. Tourism Management, 42, 37-49.

Sharpley, R., \& Naidoo, P. (2010). Tourism and poverty reduction: The case of Mauritius. Tourism and Hospitality Planning \& Development, 7(2), 145162.

Sharpley, R., \& Telfer, D. J. (2014). Tourism and development: concepts and issues (Vol. 63): Channel View Publications.Wrong

Sirakaya-Turk, E., Ingram, L., \& Harrill, R. (2008). Resident typologies within the integrative paradigm of sustaincentric tourism development. Tourism Analysis, 13(5-6), 531-544.

Sirgy, M. J., Efraty, D., Siegel, P., \& Lee, D.-J. (2001). A new measure of quality of work life (QWL) based on need satisfaction and spillover theories. Social Indicators Research, 55(3), 241-302.

Sirgy, M. J., Widgery, R. N., Lee, D.-J., \& Grace, B. Y. (2010). Developing a measure of community well-being based on perceptions of impact in various life domains. Social Indicators Research, 96(2), 295-311. 
Sirgy, M. J. (2011). Theoretical perspectives guiding QOL indicator projects. Social Indicators Research, 103(1), 1-22.

Skevington, S. M., Lotfy, M., \& O'Connell, K. A. (2004). The World Health Organization's WHOQOL-BREF quality of life assessment: psychometric properties and results of the international field trial. A report from the WHOQOL group. Quality of life Research, 13(2), 299-310.

Smith, L. T. (1999). Decolonizing methodologies: Research and indigenous peoples: Zed books. London

Spradley, J. P. (2016). The ethnographic interview. 1979.Belmont, CA: Wadsworth.

Suntikul, W., Pratt, S., I Kuan, W., Wong, C. I., Chan, C. C., Choi, W. L., \& Chong, O. F. (2016). Impacts of tourism on the quality of life of local residents in Hue, Vietnam. Anatolia, 27(4), 405-420.

Swain, M. B. (2009). The cosmopolitan hope of tourism: Critical action and worldmaking vistas. Tourism Geographies, 11(4), 505-525.

Tracy, S. J. (2012). Qualitative research methods: Collecting evidence, crafting analysis, communicating impact: John Wiley \& Sons. New Jersey

Tracy, S. J. (2013). Qualitative research methods. UK: Wiley-Blackwell.

Tyrrell, T., Paris, C. M., \& Biaett, V. (2013). A quantified triple bottom line for tourism: Experimental results. Journal of travel research, 52(3), 279-293.

Urtasun, A., \& Gutiérrez, I. (2006). Tourism agglomeration and its impact on social welfare: An empirical approach to the Spanish case. Tourism Management, 27(5), 901-912.

Usher, L. E., \& Kerstetter, D. (2014). Residents' perceptions of quality of life in a surf tourism destination: A case study of Las Salinas, Nicaragua. Progress in Development Studies, 14(4), 321-333.

Uysal, M., Perdue, R., \& Sirgy, M. J. (Eds.). (2012). Handbook of tourism and quality-of-life research: Enhancing the lives of tourists and residents of host communities. Springer Science \& Business Media. New York. 
Uysal, M., Sirgy, M. J., Woo, E., \& Kim, H. L. (2016). Quality of life (QOL) and well-being research in tourism. Tourism Management, 53, 244-261.

Var, T., \& Kim, Y. (1989). Measurement and findings on the tourism impact. Unpublished Paper, Department of Recreation, Park and Tourism Sciences, Texas A\&M University, College Station.

Varley, R. C. G. (1977). Tourism in Fiji: Some Economic and Social Problems. Bangor Occasional Papers in Economics, 12.

Veenhoven, R. (2000). Freedom and happiness: A comparative study in forty-four nations in the early 1990s. Culture and subjective well-being, 257-288. Wrong

Voelklein, C., \& Howarth, C. (2005). A review of controversies about social representations theory: A British debate. Culture \& Psychology, 11(4), 431454.

Vogt, C., Jordan, E., Grewe, N., \& Kruger, L. (2016). Collaborative tourism planning and subjective well-being in a small island destination. Journal of Destination Marketing \& Management, 5(1), 36-43.

Waddington, D. (1994). Participant Observation. IN CASSELL, C. \& SYMON, G.(Eds.) Qualitative Methods in Organizational Research: A Practical Guide. Thousand Oaks, California

Wall, G., \& Mathieson, A. (2006). Tourism: change, impacts, and opportunities. Pearson Education. London

Weaver, D. B., \& Lawton, L. J. (2001). Resident perceptions in the urban-rural fringe. Annals of Tourism Research, 28(2), 439-458.

Weiermair, K., \& Peters, M. (2012). Quality-of-life values among stakeholders in tourism destinations: A tale of converging and diverging interests and conflicts. In Handbook of tourism and quality-of-life research (pp. 463473). Springer, Dordrecht.

Wilkinson, K. P. (1991). The community in rural America: Greenwood Publishing Group. Connecticut. 
Wish, N. B. (1986). Are We Really Measuring the Quality of Life? Well-being Has Subjective Dimensions, As Well As Objective Ones. American Journal of Economics and Sociology, 45(1), 93-99.

Whitford, M., \& Ruhanen, L. (2016). Indigenous tourism research, past and present: Where to from here? Journal of Sustainable Tourism, 24(8-9), 1080-1099.

Woo, E., Kim, H., \& Uysal, M. (2015). Life satisfaction and support for tourism development. Annals of Tourism Research, 50, 84-97.

World Health Organisation, 2019. Retrieved on $15^{\text {th }}$ December, 2019 from https://www.who.int/healthinfo/survey/whoqol-qualityoflife/en/

World Travel and Tourism Council (2015) Travel and Tourism 2015 Report. London.

Yabaki, T. (2006). Women's life in a Fijian village. University of Canberra. Canberra.

Yu, C.-P., Chancellor, H. C., \& Cole, S. T. (2011). Measuring residents' attitudes toward sustainable tourism: A reexamination of the sustainable tourism attitude scale. Journal of Travel Research, 50(1), 57-63.

Yin, R. K. (2011). Applications of case study research. sage.

Zeppel, H. (1998). Land and culture: Sustainable tourism and indigenous peoples. Land and culture: sustainable tourism and indigenous peoples., 60-74. Wrong 